\title{
Interleukin 6 and Interleukin 17a Enhance Proliferation and Differentiation of Murine Osteoblast and Human Foetal Osteoblast Cell Lines
}

\author{
Shaminea $S^{a}$, Kannan TPa, Norazmi MN ${ }^{b, c}$, Nurul AA ${ }^{b}$ \\ ${ }^{a}$ School of Dental Sciences, Universiti Sains Malaysia, 16150 Kubang Kerian, Kelantan, Malaysia \\ ${ }^{b}$ School of Health Sciences and Institute for Research in Molecular Medicine, Universiti Sains Malaysia, 16150 \\ Kubang Kerian, Kelantan, Malaysia
}

\begin{abstract}
Introduction: Cytokines have been gaining great focus due to their role in enhancing osseointegration as well as their potential in bone reconstruction. Osseointegration often faces complications in its compatibility with the implant due to rejection by the recipients own immune system. Therefore, extensive studies are being carried out to enhance osteoblast development to minimize such complication. The aim of this study was to determine the effect of different concentrations of Interleukin 6 (IL-6) and Interleukin 17a (IL-17A) in the proliferation and differentiation of murine and human osteoblasts. Methods: Various concentrations (5, 10, $25 \mathrm{and} 50 \mathrm{ng} / \mathrm{ml}$ ) of rIL-6 and rIL-17A were tested on both murine osteoblast (MC3T3-E1) and human feotal osteoblast (hFOB) cell lines using [3-(4,5-dimethylthiazol-2-yl)-5-(3-carboxymethoxyphenyl)-2-(4-sulfophenyl)-2H-tetrazolium] (MTS) and alkaline phosphatise (ALP) assays. MTS was carried out at 24, 48, 72, 96 and 120 hours while ALP assay was done on day 1, 3, 7, 10 and 14. Results: MC3T3-E1 cells showed steadier proliferation and differentiation compared to hFOB. Both cell lines expressed responses in dose-dependent manner. The concentration of $10 \mathrm{ng}$ for IL-6 and IL-17A in the case of MC3T3-E1 cell line was found to be the most suitable for further studies. Conclusion: IL-6 and IL-17A enhance proliferation and ALP activity of both MC3T3-E1 and hFOB cell lines.
\end{abstract}

KEYWORDS: Cytokines, differentiation, interleukin-6, interleukin-17, osteoblast

\section{INTRODUCTION}

Osteoblasts influence the initiation and mineralization of bone at early stage of development followed by bone remodelling. Osteoblasts also regulate osteoclast differentiation and resorption. ${ }^{1}$ It typically modulates the activities or mechanisms involved via cytokine secretion. ${ }^{2}$ Aberration in the mechanism involves may disrupt intercellular communication between cells, leading to many bone related diseases such as rheumatoid arthritis, osteoporosis, osteopetrosis and Paget's disease. ${ }^{3}$ Thus a controlled and balanced regulation of osteoblast formation and identification of its specified role in osteogenesis may help as basis strategies in preventing such conditions. Identifying the enhancing precursor such as appropriate signalling messenger towards the osteoblast formation is also essential to overcome bone disruption. ${ }^{4}$

Corresponding author:

Dr. Nurul Asma Abdullah, School of Health Sciences, Universiti Sains Malaysia, 16150 Kubang Kerian, Kelantan, Malaysia

E-mail: nurulasma@usm.my

Tel: +609767 7838 Fax: +609767 7515
Cytokines play a vital role in the interaction between cells, where they stimulate the activities of different tissues and cell types. They act as chemical communicators between cells by producing signals as messengers for cells to trigger appropriate response. ${ }^{5}$ Cytokines are also capable of modulating immune response where they act as pro-inflammatory or antiinflammatory agent. ${ }^{6}$ Lately, cytokines have been identified as the key mediator in the proliferation and differentiation of osteoblast precursors. ${ }^{7}$ Interestingly, the same cytokines which play a vital role in bone formation might also be involved in bone resorption under certain circumstances. ${ }^{8}$ Studies indicated that increased levels of selected cytokines may lead to the activation of bone resorption. ${ }^{9}$ In some cases, although cytokines enhance bone cell proliferation, they exhibit negative effects on mature osteoblast function. ${ }^{10}$

IL-6 is one of the dynamic potent activator cytokine which has received a great deal of focus in the field of cell signalling and immunogenic pathways. ${ }^{11}$ This multifunctional cytokine is secreted by T-cells and macrophages. Besides their distinct role in gene activation, IL- 6 regulates the proliferation and differentiation of cells and tissues. ${ }^{10}$ Hence, various studies have proven that IL- 6 has the tendency to act as either enhancer or inhibitor influencing osteoblast activity depending on the condition. Under certain 
circumstances, it is involved in RANK signalling pathways to stimulate osteoblast proliferation and differentiation. ${ }^{12}$ According to Shaama, ${ }^{10} \mathrm{IL}-6$ triggers osteoclastogenesis in the presence of other precursors. It is also proven that the IL-6 is secreted by osteoblasts when stimulated by other cytokines that initiates osteoclast formation. Therefore, IL-6 is capable of indirectly functioning as a potent osteoclast stimulator and the activity of IL-6 may depend on the influence of various parameters and the materials applied. ${ }^{13}$

IL-17 is a cytokine distinguished by its key role in tissue inflammation and immunologic reaction. ${ }^{14}$ Unlike other cytokines, it is produced by memory T-cells and is a well known pro-inflammatory cytokine. ${ }^{15} \mathrm{IL}-17$ receptors are present in osteoblasts and the cytokines plays a crucial role in bone metabolism. ${ }^{16}$ Studies have also indicated that $\mathrm{IL}-17$ is a bone acting cytokine. ${ }^{17}$ Although IL-17 is predicted to be more favourable for bone disruption, it has also been proven as a protective precursor in bone loss. IL-17 may therefore be potentially useful in overcoming bone complication. ${ }^{18}$ IL-17 could act as a retroactive mechanism which could modify bone resorption into bone formation phase. ${ }^{19}$ Therefore, additional studies on the modulatory properties of IL-6 and IL-17 are needed to understand bone metabolism and osteoblasts formation.

The aim of this study was to gauge the effects of the two cytokines, IL- 6 and IL-17A on osteoblast proliferation and differentiation using the murine osteoblast cell lines (MC3T3-E1) and human foetal osteoblast (hFOB 1.19).

\section{MATERIALS AND METHODS}

\section{Cell culture preparation}

Murine osteoblast (MC3T3-E1) and human foetal osteoblast (hFOB1.19) cell lines were cultured under sterile conditions in a controlled $37^{\circ} \mathrm{C}$ temperature and $5 \% \mathrm{CO}_{2}$ humidified atmosphere. The MC3T3-E1 and hFOB were cultured in Dulbeccos Modified Eagles Medium (DMEM) (GIBCO, UK) and Alpha minimum essential medium (a-MEM) (Nacalai Tesque, Japan) respectively. These cultures were supplemented with $10 \%$ heatinactivated foetal bovine serum (GIBCO, UK) and 1\% penicillin/streptomycin antibiotics. The medium was changed every 3 days. After harvesting and washing, the cells were exposed to different concentrations (5, 10,25 and $50 \mathrm{ng} / \mathrm{ml}$ ) of cytokines, rIL-6 and rIL-17A.

\section{Cell counting}

Upon confluence, the cells were detached using Trypsin trypLE express (GIBCO, Denmark). Cell number and cell viability were determined by Trypan blue assay. The cells were stained with $0.4 \%$ Trypan blue solution (Sigma-Aldrich, UK) and then transferred to a disposable Countess $^{\mathrm{TM}}$ cell counting chamber slide and counted by Countess ${ }^{\circledR}$ Automated Cell Counter (Invitrogen Corp, USA).

\section{Cell proliferation assay}

Proliferation of viable cells was estimated by [3-(4,5-di- methylthiazol-2-yl)-5-(3-carboxymethoxyphenyl)-2-(4sulfophenyl)-2H-tetrazolium] MTS assay (Promega, CellTiter $96^{\circledR}$ aqueous non-radioactive cell proliferation assay). Approximately 5000 cells were seeded into each well in $100 \mu$ culture media. Then, various concentrations of rIL-6 and rIL-17A (5, 10, 25 and 50 $\mathrm{ng} / \mathrm{ml}$ ) were added into each well respectively. The samples were prepared in quadruplicates along with a control group consisting of growth media alone. The cells were incubated for 24, 48, 72, 96 and 120 hours respectively. During the selective incubation period, MTS (Promega, USA) was added to each well. After 4 hours of incubation in $5 \% \mathrm{CO}_{2}$ incubator, the absorbance of each solution was measured at the wavelength of $490 \mathrm{~nm}$ by ELISA plate reader (SunRise, Tecan, Austria). Proliferation Index was calculated by dividing the OD value of each sample by the OD value of the control and multiplying the result with 100 .

\section{Alkaline phosphatase assay}

Activity of cells was measured by alkaline phosphatase (ALP) activity assay by quantifying the release of $p$-nitrophenol.Precisely, $100 \mu$ lof culturemedia was transferred into a 96-well plate (in quadruplicates) and 5000 cells were seeded into each well and incubated at $37^{\circ} \mathrm{C}$ in $5 \% \mathrm{CO}_{2}$. The cells were incubated for 14 days. The analysis of ALP assay was performed at day 1, 3, 7, 10 and 14. During the selected incubation periods, the samples were washed with PBS and Triton X-100 (0.5\%; Sigma) was added to each well to lyse the cells. Following two freeze-thaw cycles at $80^{\circ} \mathrm{C}$ at 15 minutes interval to homogenize the cells, $15 \mu$ l of ALP substrate solution (Randox, UK) was added into each well and incubated for 1 hour in $5 \% \mathrm{CO}_{2}$ incubator. Finally, $1 \mathrm{M} \mathrm{NaOH}$ stop solution was added to stop the reaction and the absorbance of each solution was measured at $405 \mathrm{~nm}$ by ELISA plate reader.

\section{Statistical analysis}

The various concentrations of IL-6 and IL-17A tested on both MC3T3-E1 and hFOB were analysed using Oneway ANOVA with post hoc Bonferroni procedures were used for multiple comparisons by IBM SPSS software version 20.0. All statistical analyses were performed at the significance level of $p<0.05$. The assumptions of normality, homogeneity of variances and compound symmetry were checked and fulfilled.

\section{RESULTS}

\section{Analysis of cell proliferation}

The analysis of cell proliferation in both MC3T3-E1 and hFOB treated with various concentrations $(5,10,25$ and $50 \mathrm{ng} / \mathrm{ml}$ ) of IL-6 and IL-17A respectively after 24, 48, 72, 96 and 120 hours incubation is shown in Figure 1 (a-d). The percentage of cell proliferation showed less difference among the studied concentrations of IL-6 and L-17A. Interestingly, all treated groups showed a higher percentage of cell viability $(>100 \%)$ compared to the control group, indicating that there was no cytotoxicity effect by cytokines. Both cytokines promoted the cell proliferation in a dose dependent 
a)

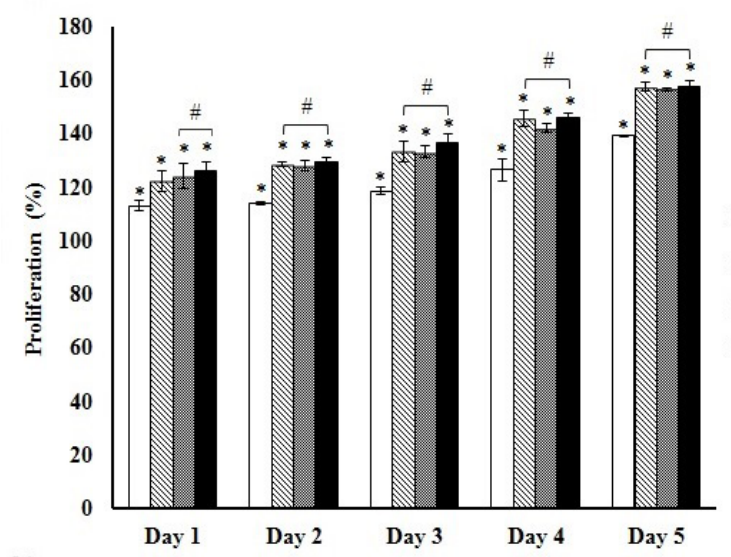

b)

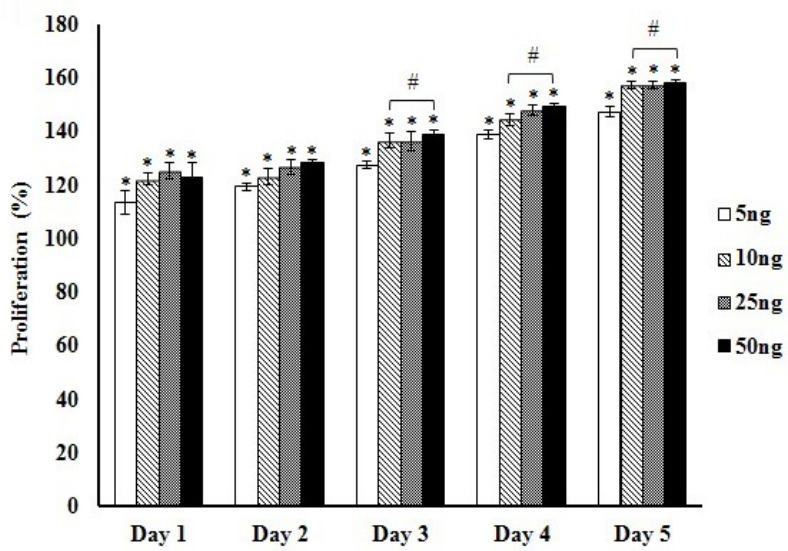

c)

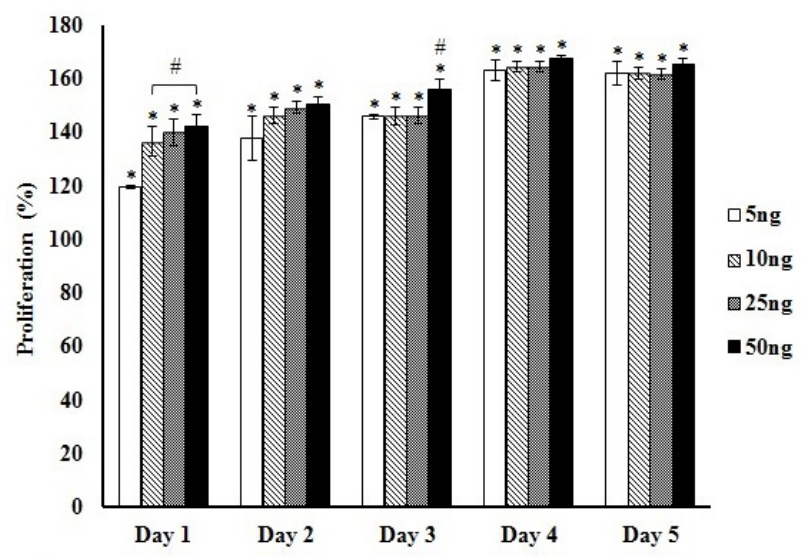

d)

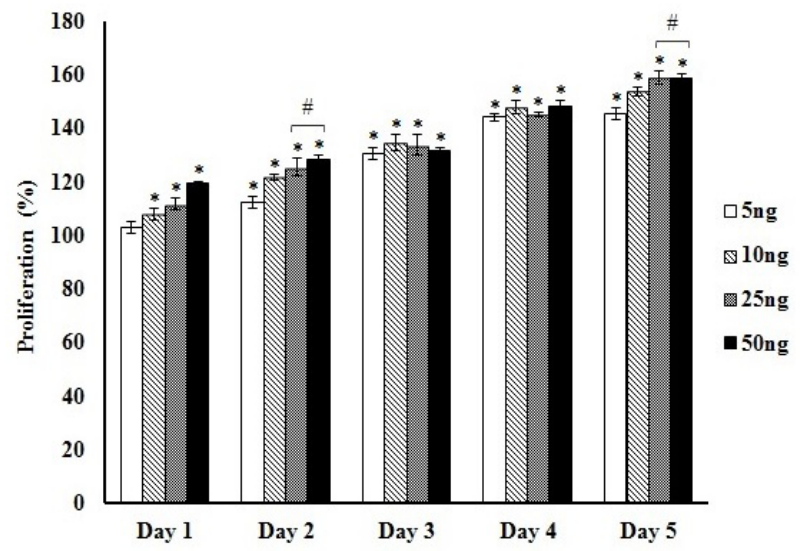

Figure 1. Effects of various concentrations of IL- 6 and IL-17A on MC3T3-E1 and hFOB cell line for a period of 5 days. (a) Proliferation assay of IL-6 on MC3T3-E1 cell line. (b) Proliferation assay of IL-17A on MC3T3-E1 cell line. (c) Proliferation assay of IL-6 on hFOB cell line. (d) Proliferation assay of IL-17A on hFOB cell line. Cells with media alone were used as a control. The data presented as mean \pm S.D. of quadruplicate cultures. ${ }^{*} p<0.05$ indicates significant difference from the control and \#p $<0.05$ indicates significant difference within the treated groups.

\section{Analysis of alkaline phosphatase activity}

The effect of ALP activity due to IL-6 and IL-17A on the MC3T3-E1 and hFOB cell lines was observed. The cells were treated with various concentrations $(5,10,25$ and $50 \mathrm{ng} / \mathrm{ml})$ of IL- 6 and IL-17A respectively. ALP activity was observed on day $1,3,7,10$ and 14 as shown in Figure $2(\mathrm{a}-\mathrm{d})$. The ALP assay showed that the cells treated with cytokines secreted higher level of ALP compared to control group. The level of ALP activity was increased in dose dependent manner in both the groups. Day 14 showed higher ALP activity than day 1, 3, 7 and 10. 
a)

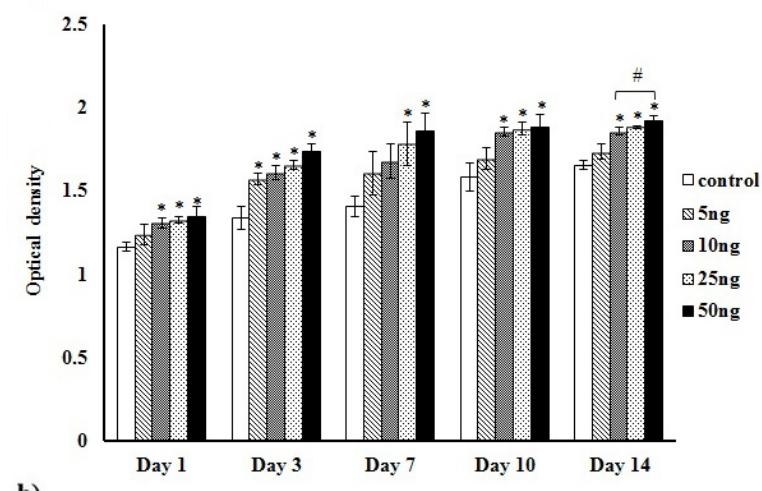

b)

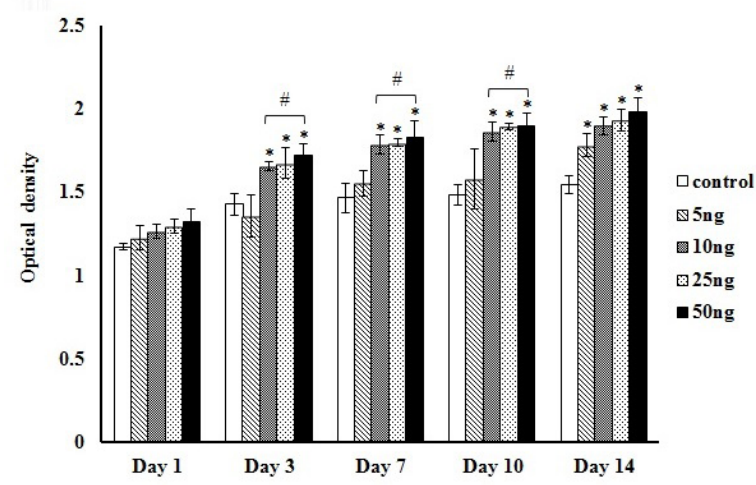

c)

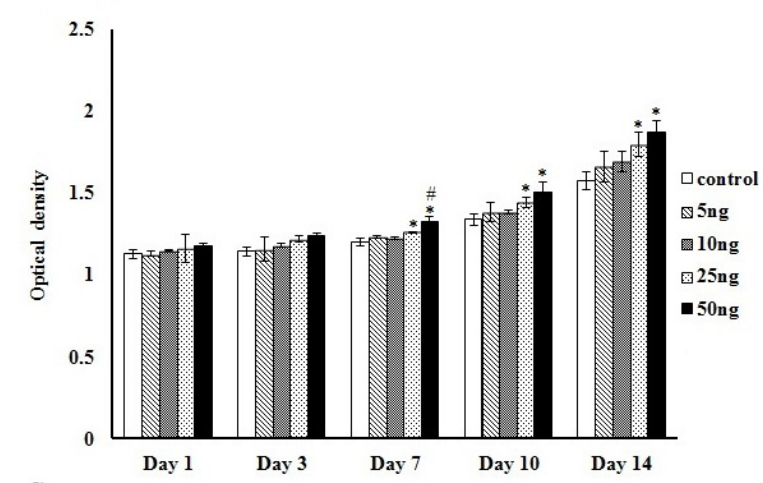

d)

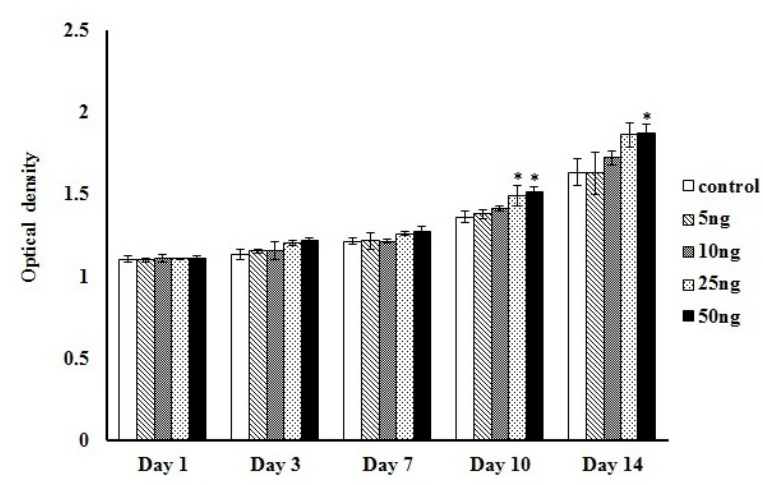

Figure 2. Effects of IL-6 and IL-17A on MC3T3-E1 and hFOB cell line for 14 days period. (a) ALP assay of IL-6 on MC3T3-E1 cell line. (b) ALP assay of IL-17A on MC3T3-E1 cell line. (c) ALP assay of IL-6 on hFOB cell line. (d) ALP assay of IL-17A on hFOB cell line. ALP activity was measured during the early proliferation period day $1,3,7$ and during osteoblastic differentiation period day 10, 14. Cells with media alone were used as control. The data presented as mean \pm S.D. of quadruplicate cultures. ${ }^{*} p<0.05$ indicates significant difference from the control and \#p $<0.05$ indicates significant difference within the treated groups.

\section{DISCUSSION}

The role of IL-6 and IL-17A in regulating osteoblast cell proliferation and differentiation has not been well understood in the past. Our study demonstrated the effects of various concentrations of IL-6 and IL-17A cytokines on proliferation (MTS assay) and osteoblast differentiation (ALP assay). Both cytokines enhanced the proliferation and differentiation and is expected to be involved in mineralization of osteoblast.

Using MTS assay we showed that MC3T3-E1 and hFOB proliferated at a significantly higher level in the presence of IL- 6 and IL-17A cytokines. The highest treated concentration of $50 \mathrm{ng} / \mathrm{ml}$ showed a high viability percentage compared with other treated groups. This study indicated that treatments with IL-6 or IL-17A were not cytotoxic to cells either at low or high concentrations. Therefore, all the concentrations $50 \mathrm{ng} / \mathrm{ml}, 25 \mathrm{ng} / \mathrm{ml}, 10 \mathrm{ng} / \mathrm{ml}$ and $5 \mathrm{ng} / \mathrm{ml}$ of cytokines tested in this study do not exhibit any cytotoxic effect on both the cell lines.

Alkaline phosphatase (ALP) is a multifunctional enzyme that hydrolyzes phosphate substrate to enhance calcium formation which forms the bone mineral. ${ }^{20}$ It is often used as an important marker for osteoblast activity which is released during bone formation. During osteogenic differentiation, ALP is involved in the differentiation pathway by expressing matrix-associated proteins which is released during bone mineralization. ${ }^{21}$ In this study, high levels of ALP were released by both cytokine treated MC3T3-E1 and hFOB cell lines compared to untreated control suggesting that these cytokines were effective regulators for bone formation (Figure 2).

IL-6 is a pro-inflammatory and anti-inflammatory cytokine produced by $\mathrm{T}$ cells and macrophages. It regulates inflammation, immune responses and bone homeostasis. $^{22}$ It is believed to influence both osteoblast and osteoclast differentiation based on many findings via RANK signalling pathway ${ }^{12}$. In this study, it was found that IL-6 promoted differentiation of both the cell lines. Conversely, IL-17A also plays a major role in bone remodelling and unlike IL-6, it is more favourable towards osteoclastogenesis in in vivo studies. ${ }^{23}$ This study proved that IL-17 is involved in the proliferation and differentiation of osteoblast cells in vitro under controlled condition. Both IL-6 and IL-17A cytokines is cell compatible and stimulates osteoblast differentiation and mineralization. The level of ALP activity was increased in a dose dependent manner for both groups, indicating that these cytokines presented osteogenic properties and promoted mineralization of tissue formation. hFOB treated plates, at day 10 and 14 showed higher ALP activity than day 1,3 and 7 . This could indicate a 
pattern resembling the bone mineralization activity, where ALP secretion gradually increases in the treated groups. ${ }^{20}$ Interestingly, day 14 expressed a relatively higher ALP activity than others. The peak in ALP activity generally denotes the initiation stage of bone mineralization. In this case, such rapid increased pattern in ALP activity was recorded on day 14 which supports osteogenic induction and evidently the mineralization on the samples. ${ }^{20}$ In contrast, treated MC3T3-E1 group showed a gradual increase from day 1 to day 14 , as day 14 recorded the optimal ALP activity validating mineralization initiation. High proliferation was expressed by all the concentrations of cytokines compared to untreated groups overall in this study. Hence, for MC3T3-E1 $10 \mathrm{ng} / \mathrm{ml}$ for IL-6 and IL-17A is found suitable for further studies as no significant difference was observed among $10 \mathrm{ng} / \mathrm{ml}, 25 \mathrm{ng} / \mathrm{ml}$ and $50 \mathrm{ng} / \mathrm{ml}$ concentrations tested.

\section{CONCLUSIONS}

The efficacy of IL-6 and IL-17A cytokines to trigger response towards osteoblast proliferation, differentiation and indirect involvement in mineralization can be interpreted from the findings. It is apparent that these cytokines do not cause any cytotoxicity to the MC3T3-E1 and hFOB cells. The differences in various concentration levels and their activity towards the proliferation and differentiation have less effect overall in this study. However, application of cytokines as growth inducer in bone formation is highly promising and has the tendency to enhance osseointegration. Thus, there are possibilities for these cytokines to be an excellent regulator for orthopaedic and dental applications in cell adhesion and bone growth. Further studies on its effects in merging or incorporating biomaterial into bone, is necessary to firmly establish the utilization of cytokines to achieve more functions for bone studies.

\section{ACKNOWLEDGEMENTS}

We would like to thank the staff of Craniofacial Sciences Laboratory, School of Dental Sciences, Universiti Sains Malaysia for their help rendered in this study. This study was financially supported by Fundamental Research Grant Scheme (FRGS) from Ministry of Higher Education, Malaysia (203/ PPSG /6171134).

\section{REFERENCES}

1. Neve A, Corrado A, Cantatore F. Osteoblast physiology in normal and pathological conditions. Cell Tissue Res 2011; 343:289-302.

2. Tokuda H, Kozawa O, Uematsu T. Interleukin (IL)-17 enhances prostaglandin F(2 alpha)stimulated IL-6 synthesis in osteoblas Prostaglandins Leukot Essent Fatty Acids 2002;66: 427-33

3. Phan TC, Xu J, Zheng MH. Interaction between osteoblast and osteoclast: impact in bone disease. Histol Histopathol 2004; 19:1325-44.

4. Mackie EJ. Osteoblasts: novel roles in orchestration of skeletal architecture. Int J Biochem Cell Biol 2003; 35:1301-5.

5. Debets R, Savelkoul HFJ. Cytokines as cellular communicators. Mediators Inflamm 1996; 5:41723.

6. Dinarello CA. Proinflammatory cytokines. Chest 2000; 118:503-8.

7. Heinrich PC, Behrmann I, Haan S, et al. Principles of interleukin (IL)-6-type cytokine signalling and its regulation. Biochem J 2003; 374:1-20.

8. Manolagas SC, Jilka RL. Bone marrow, cytokines, and bone remodeling. Emerging insights into the pathophysiology of osteoporosis. New Engl J Med 1995; 332:305-11.

9. Manolagas SC, Jilka RL, Girasole G, Passed G, Bellido T. Estrogen, cytokines, and the control of osteoclast formation and bone resorption in vitro and in vivo. Osteoporosis Int 1993; 3:114-6.

10. Shaama FA. An in vitro comparison of implant materials cell attachment, cytokine and osteocalcin production. West Indian Med J 2005; 54:250-6.

11. Hirano T, Ishihara K, Hibi M. Roles of STAT3 in mediating the cell growth, differentiation and survival signals relayed through the IL- 6 family of cytokine receptors. Oncogene 2000; 19:2548-56.

12. Yoshitake F, Itoh S, Narita H, Ishihara K, Ebisu S. Interleukin-6 directly inhibits osteoclast differentiation by suppressing receptor activator of NF-kappaB signaling pathways. J Biol Chem 2008; 283:11535-40.

13. Frost $A$, Jonsson $K B$, Brandstrom $\mathrm{H}$, et al. Interleukin (IL)-13 and IL-4 inhibit proliferation and stimulate IL- 6 formation in human osteoblasts: evidence for involvement of receptor subunits IL-13R, IL-13 Ralpha, and IL-4Ralpha. Bone 2001; 28:268-74.

14. Haas JD, Ravens S, Duber S, et al. Development of interleukin-17-producing gammadelta T cells is restricted to a functional embryonic wave. Immunity 2012; 37:48-59.

15. Huang H, Kim HJ, Chang EJ, et al. IL-17 stimulates the proliferation and differentiation of human mesenchymal stem cells: implications for bone remodeling. Cell Death Differ 2009; 16:1332-43.

16. Van bezooijen RL, Farih-Sips HC, Papapoulos SE, Lowik CW. Interleukin-17: A new bone acting cytokine in vitro. $\mathrm{J}$ Bone Miner Res 1999; 14:1513-21.

17. Shen F, Ruddy MJ, Plamondon P, Gaffen SL. Cytokines link osteoblasts and inflammation: microarray analysis of interleukin-17- and TNF-ainduced genes in bone cells. J Leukoc Biol 2005; 77:388-99.

18. Goswami J, Hernandez-Santos N, Zuniga LA, Gaffen SL. A bone-protective role for IL-17 receptor signaling in ovariectomy-induced bone loss. Eur J Immunol 2009; 39:2831-9.

19. Kwan Tat S, Pelletier JP, Amiable N, et al. Activation of the receptor EphB4 by its specific 
ligand ephrin B2 in human osteoarthritic subchondral bone osteoblasts. Arthritis Rheum 2008; 58:3820-30.

20. Mathews S, Bhonde R, Gupta PK, Totey S. Extra cellular matrix protein mediated regulation of the osteoblast differentiation of bone marrow derived human mesenchymal stem cells. Differentiation 2012; 84:185-92.

21. Marom R, Shur I, Solomon R, Benayahu D. Characterization of adhesion and differentiation markers of osteogenic marrow stromal cells. J Cell Physiol 2005; 202:41-8.

22. Axmann R, Bohm C, Kronke G, et al. Inhibition of interleukin-6 receptor directly blocks osteoclast formation in vitro and in vivo. Arthritis Rheum 2009; 60:2747-56.

23. Daoussis D, Andonopoulos AP, Liossis SN. Wnt pathway and IL-17: novel regulators of joint re modeling in rheumatic diseases. Looking beyond the RANK-RANKL-OPG axis. Semin Arthritis Rheum 2010; 39:369-83. 